\title{
PERSPECTIVE
}

\section{Evaluating the Accountable Health Communities Demonstration Project}

\author{
Laura Gottlieb, $M D, M P H^{7}$, Jeffrey D. Colvin, $M D, F A A P^{2}$, Eric Fleegler, $M D, M P H^{3}$, \\ Danielle Hessler, $P h D^{7}$, Arvin Garg, MD', and Nancy Adler, $P h D^{5}$
}

'Department of Family and Community Medicine, University of California, San Francisco, San Francisco, CA, USA; ${ }^{2}$ University of Missouri-Kansas City and Children's Mercy Hospital, Kansas City, MO, USA; ${ }^{3}$ Harvard Medical School and Boston Children's Hospital, Boston, MA, USA; ${ }^{4}$ Boston University School of Medicine, Boston, MA, USA; ${ }^{5}$ Center for Health and Community and the Department of Psychiatry, University of California, San Francisco, San Francisco, CA, USA.

Despite substantial evidence documenting the social patterning of disease, relatively little information is available on how the health care system can best intervene on social determinants to impact individual and population health. Announced in January 2016, the Centers for Medicare and Medicaid Innovation's (CMMI) Accountable Health Communities (AHC) initiative provides an important opportunity to improve the evidence base around integrated social and medical care delivery. To maximize learning from this largescale demonstration, comprehensive evaluation efforts should focus on effectiveness and implementation research by supporting local, regional, and national studies across a range of outcomes. Findings from this demonstration could transform how, when, and which patients' health-related social needs are addressed within the health care delivery system. Such findings would strongly complement other initiatives to address social factors outside of health care.

J Gen Intern Med 32(3):345-9

DOI: $10.1007 / \mathrm{s} 11606-016-3920-y$

(c) Society of General Internal Medicine 2016

A substantial body of evidence links social circumstances to health and longevity. ${ }^{1-3}$ Mortality estimates associated with social factors are comparable in magnitude to those associated with myocardial infarction, cerebrovascular disease, or lung cancer. ${ }^{4-6}$ At the same time, there is national concern about the expense and deficiencies of traditional health care services. ${ }^{7}$ Together, these forces are fueling interest in addressing social determinants of health (SDH) within the health care delivery system. While recognizing that work to improve social conditions occurs outside of health care settings, ${ }^{5}$ health professional organizations have recommended better integration of medical and social care delivery systems as one part of a comprehensive strategy to identify and address $\mathrm{SDH} .^{8-10}$

Clinical delivery systems are increasingly experimenting with ways to address SDH in the clinical delivery system. ${ }^{11-}$

Received July 18, 2016

Revised October 12, 2016

Accepted October 27, 2016

Published online November 14, 2016
${ }^{13}$ However, little research has examined whether these efforts improve individual and population health, decrease avoidable utilization, and/or improve revenue under value-based payment systems. ${ }^{11,12}$ To respond to the disconnect between this growing interest in addressing SDH in the health care setting and gaps in effectiveness evidence, in January of 2016, the Centers for Medicare and Medicaid Services Innovation (CMMI) announced an initiative to test a new model of care that includes health-based social needs screening and resource navigation for Medicare and Medicaid beneficiaries. ${ }^{14}$ The financial investment in the CMMI Accountable Health Communities (AHC) initiative totals $\$ 157$ million over 5 years and presents an important opportunity to fill evidence gaps.

In this article, we outline the CMMI AHC demonstration project and anticipated CMMI evaluation outcomes metrics. We then provide a rationale for examining a wider range of effectiveness and implementation outcomes and highlight opportunities and challenges facing this broader research agenda. This article emerged from a meeting of 25 affiliates (complete list included in the Acknowledgements section) of the Social Interventions Research and Evaluation Network (SIREN), a national collaborative convened to catalyze and strengthen research on social screening and interventions in health care delivery settings. Supported by the Robert Wood Johnson Foundation and Kaiser Permanente, SIREN includes researchers and practitioners from health services, public health, social and behavioral determinants of health, and philanthropy. In the meeting, participants discussed existing evidence and gaps regarding the impact of health care-based interventions addressing social needs and opportunities for evaluation embedded in the new AHC demonstration.

\section{EVALUATION OPPORTUNITIES}

The AHC initiative will include social interventions in 44 sites involving over 3 million patients annually. Impact evaluations, whether supported through CMMI or externally, can take advantage of the sophisticated and rigorous research designs, metrics, and data sharing requirements outlined in the original funding announcement. ${ }^{15}$ There are three funded program tracks that involve varying degrees of resource navigation 
and support. Two of the three tiers require randomization of participants, and the third track requires a matched controlled design (see Table 1, Accountable Health Communities Program Tracks). In the announcement, CMMI provides a stepby-step guide to help health care systems prioritize activities necessary to develop systems for screening, referral, and navigation services, including building a community resource inventory, hiring screening and referral specialists, and training in-person navigators. CMMI also defines five core social needs domains (housing, food security, transportation, interpersonal violence, and utilities) that must be included in grantees' screening and intervention programs. Sites are required to use standardized social screening items for these domains that will be developed by a national Technical Expert Panel (TEP). The TEP convened in the summer of 2016 and is comprised of 22 participants with expertise in health-related social needs and referral systems. Participants included physicians, nurses, psychologists, social workers, epidemiologists, and others drawn from medical centers, health care plans, nonprofit organizations, and academic institutions.
CMMI also will require that Medicaid and Medicare claims data be shared with AHC evaluators. Together, these requirements set the stage for enabling evaluation of the health care utilization impacts of addressing social needs. CMMI has reported publicly that model performance metrics will include total cost of care and health care utilization-including emergency department visits, inpatient admissions, readmission, and utilization of outpatient services. Though provider and beneficiary experiences are referred to as performance outcomes, CMMI has not yet defined specific metrics for these domains nor specified direct health outcomes. Evaluation findings should inform whether additional resources should be invested in these innovative interventions. Beyond CMMI's commitment to program evaluation, SIREN researchers saw other opportunities to maximize learning through CMMI-funded analyses and/or supplementary local, regional, or national evaluation efforts. Below we highlight recommendations for both effectiveness and implementation research that may help inform evaluation planning.

Table 1 Accountable Health Communities Program Tracks

\begin{tabular}{|c|c|c|c|c|c|}
\hline $\begin{array}{l}\text { Track no. } \\
\text { (anticipated } \\
\text { number of } \\
\text { awards) }\end{array}$ & Primary focus & $\begin{array}{l}\text { Intervention } \\
\text { characteristics }\end{array}$ & $\begin{array}{l}\text { Number of screened } \\
\text { beneficiaries/year }\end{array}$ & $\begin{array}{l}\text { Total } \\
\text { award } \\
\text { amount/ } \\
\text { awardee }\end{array}$ & Evaluation design \\
\hline Awareness (12) & $\begin{array}{l}\text { Community resource } \\
\text { information disseminated } \\
\text { to Medicaid and Medicare } \\
\text { beneficiaries with unmet } \\
\text { social needs to increase } \\
\text { awareness of social } \\
\text { services }\end{array}$ & $\begin{array}{l}\text { Universal social screening } \\
\text { for all Medicare and } \\
\text { Medicaid beneficiaries and } \\
\text { community resource referrals }\end{array}$ & $53,000^{\dagger}$ & $\$ 1.17 \mathrm{M}$ & $\begin{array}{l}\text { Both high- and low-risk } \\
\text { patients with unmet social } \\
\text { needs are randomized into } \\
\text { awareness (community re- } \\
\text { source referrals) versus } \\
\text { comparison (control) } \\
\text { groups }\end{array}$ \\
\hline Assistance (12) & $\begin{array}{l}\text { Community service } \\
\text { navigation services } \\
\text { available to assist high-risk } \\
\text { beneficiaries with social } \\
\text { needs }\end{array}$ & $\begin{array}{l}\text { Universal social screening } \\
\text { for all Medicare and } \\
\text { Medicaid beneficiaries, } \\
\text { community resource } \\
\text { referrals, and intensive } \\
\text { navigation services }\end{array}$ & $75,000^{\dagger}$ & $\$ 2.57 \mathrm{M}$ & $\begin{array}{l}\text { All patients with unmet } \\
\text { social needs receive } \\
\text { community resource } \\
\text { referrals; high-risk patients } \\
\text { are randomized into assis- } \\
\text { tance (community service } \\
\text { navigation) versus aware- } \\
\text { ness (control) groups }\end{array}$ \\
\hline Alignment (20) & $\begin{array}{l}\text { Encourage partner } \\
\text { alignment to ensure service } \\
\text { availability for beneficiaries }\end{array}$ & $\begin{array}{l}\text { Universal social screening } \\
\text { for all Medicare and } \\
\text { Medicaid beneficiaries; } \\
\text { community resource } \\
\text { referrals, navigation services } \\
\text { and community-level inte- } \\
\text { gration activities. Partner } \\
\text { alignment depends on quali- } \\
\text { ty improvement approaches, } \\
\text { including advisory board and } \\
\text { data sharing, focused on en- } \\
\text { suring social services are } \\
\text { available based on popula- } \\
\text { tion needs }\end{array}$ & $\begin{array}{l}75,000^{\dagger} \text { and at least } \\
51 \% \text { of community- } \\
\text { dwelling Medicare } \\
\text { and Medicaid bene- } \\
\text { ficiaries }\end{array}$ & $\$ 4.51 \mathrm{M}$ & $\begin{array}{l}\text { High-risk }{ }^{\dagger} \text { patients with } \\
\text { unmet social needs receive } \\
\text { community resource } \\
\text { navigation services; low- } \\
\text { risk patients with unmet } \\
\text { social needs receive com- } \\
\text { munity resources referrals. } \\
\text { Matched comparison } \\
\text { groups and communities } \\
\text { will be assigned }\end{array}$ \\
\hline
\end{tabular}

\footnotetext{
"Community-based organizations, health care provider practices, hospitals and health systems, institutions of higher education, local government entities, tribal organizations and for-profit and not-for-profit local and national entities that have the capacity to develop and maintain a referral network with clinical delivery sites and community service providers. Applicants can be either a consortium of collaborators or a single bridge organization that will form a consortium if awarded funds. (See Accountable Health Communities Model. Centers for Medicare and Medicaid Innovation. Available at https://innovation.cms.gov/initiatives/AHCM. Accessed October 20, 2016)

"In Year 1, grantees only need to screen half this number of Medicare or Medicaid beneficiaries

"In the AHC model, to be considered "high risk," a community-dwelling beneficiary must have a health-related social need and self-report two or more ED visits in the 12-month period prior to initial social screening

${ }^{\xi}$ Required partners in any AHC Track 3 consortium include the state Medicaid agency, participating clinical delivery sites, participating community service providers, local government, and participating local payers such as Medicaid-managed care organizations and Medicare Advantage plans
} 


\section{Effectiveness Research}

Evidence is sparse on whether addressing SDH in the context of health care settings significantly impacts individual or population health. Answers to this question should help guide future investments. The guaranteed availability of claims and utilization data to researchers assessing AHCs is a major step towards enabling effective evaluation of health outcomes. Despite this, barriers remain to studying the causal chain between screening for social needs and a resulting health or utilization outcome. The pathway involves many mediating steps, each of which takes time to achieve, along with potential unmeasured confounders. Previous research into the mechanisms linking health and social factors suggests that a 5-year funding window is too short to see many of the end outcomes of interest reflected in claims and utilization data ${ }^{16}$ and may result in false-negative findings.

In addition to an expanded evaluation timeframe, several strategies can be used to diminish the likelihood of falsenegative results. One is to incorporate proximal mediating factors that are sensitive to changes in social conditions and are known to be along the pathway to better health outcomes. For example, outcomes that capture patient perspectives such as satisfaction with care and connectedness to practices are related to health care quality and increasingly relevant to health care systems in an era of consumerism in the health care industry. ${ }^{17,18}$ Other mediators involve key operational processes (e.g., patient referrals, successful connections to social resources, and tracking resolution of identified social needs). Better standardization of these process measures would help discern how the content and dose of social interventions influence health outcomes. This could also provide a clearer understanding of the "active ingredients" in social programs for different groups of patients. These process measures can be used for comparative effectiveness studies and in decisions about targeting scarce resources towards groups that may need more tailored intervention approaches.

The evaluation strategy will also need to account for the different mechanisms through which social determinants affect health. ${ }^{16}$ Some social determinants are directly tied to health outcomes, such as the detrimental effect of poor housing conditions on asthma. The impact of ameliorating those factors should be detectable using indicators such as health care utilization and missed workdays. Other social conditions have been linked to later health through prolonged exposure to adversity-induced "toxic stress." In these cases it will be more informative to use outcomes such as biomarkers of inflammatory and stress pathways, which are known to impact downstream health and can serve as markers of future morbidity. ${ }^{19-21}$ In relation to the AHC evaluation, it would be too costly to collect such data across 44 sites, but funding high-quality, local studies would markedly expand the knowledge produced by this large-scale demonstration. Stronger evidence documenting the impacts on biological markers could inform existing risk stratification tools and better target social interventions.
Although the primary evaluation thrust should be on the impact of social interventions on patient outcomes, the additional opportunity to understand impacts on health care providers should not be overlooked. Low provider-perceived capacity to address social needs is linked with higher provider burnout. ${ }^{22}$ Provider burnout and subsequent turnover, which together carry a high cost and quality burden, ${ }^{23,24}$ are particularly relevant to health care systems caring for vulnerable populations. We note that it is possible that the addition of social needs screening and interventions may not alleviate burnout and could further overwhelm health care providers serving Medicaid and Medicare beneficiaries. If so, it could increase emotional exhaustion or otherwise negatively affect professional burnout domains. The CMMI demonstration sites could add to our understanding of how increased capacity to address social needs, and the related workload, affects both provider and clinic-level outcomes (e.g., burnout, workforce retention).

\section{Implementation Research}

In addition to outcomes research, there is the potential to advance implementation science in this area. Such work examines the translation and scaling of effective programs to "real-world" settings, thus improving our understanding of why and how interventions work. ${ }^{25}$ Implementation research in this case should enable the adoption and sustainability of similar interventions in both initial CMMI grantee sites and other settings.

Implementation research should help address questions around sustainability and dissemination that will arise in the later stages of the grant period. CMMI has not clearly articulated future plans for maintaining these new community resource inventories (or the technology required to maintain them) or for supporting screening specialists and navigators when the program's 5-year funding term ends. Though the funding opportunity announcement requires state Medicaid agencies to confirm their "willingness to ensure alignment with existing Medicaid policy...to achieve scalability and sustainability if the model is successful," recent findings from interviews with Medicaid-managed care organizations (MMCO) suggest that many state regulations instead limit MMCO support of SDH interventions. ${ }^{26}$ Health policyfocused implementation research across states involved in these demonstrations will maximize future sustainability and dissemination strategies.

Implementation research will also need to examine potential unintended consequences ${ }^{27}$ including the collateral impacts of routine social screening and referrals services from health care on community agencies, not just on the health care delivery system. Since the AHC interventions ultimately depend on a robust social service delivery system, understanding the interplay between health care-based and community-based programs in various communities should be considered an essential component of sustainability research. 


\section{CONCLUSIONS}

CMMI has created the largest demonstration to date to examine the impact of health care-based interventions addressing social needs. It is an appropriately ambitious "moonshot" to fill gaps in evidence about the roles health care institutions can play in screening for and addressing social determinants that affect health. Findings from this set of studies could transform how, when, and for which patients social needs are addressed and help advance health care disparities intervention research by strengthening the evidence base about both positive and negative effects of social screening and intervention activities.

CMMI is doing its part to ensure we learn together from this investment by designing the grants program to facilitate comparisons within and across tracks. But as a non-research agency, CMMI can only do a portion of the research and evaluation needed to fill the existing evidence gaps in this field. Consistent with its mission, CMMI will contract with program evaluators to examine claims and utilization data over the next 5 years. To increase the payoff of this investment, other funding will need to be directed towards smaller-scale evaluations that are focused on key effectiveness and implementation questions.

It is more likely that research funders will support the kinds of studies noted above if CMMI clearly articulates the evaluation goals for AHC, describing what CMMI will study directly and what other research is needed. This assessment could form the basis for CMMI to encourage other government agencies (including the National Institutes of Health and the Agency for Health Care Quality and Research) and health care-focused philanthropic organizations to leverage the CMMI investment by dedicating research dollars to studying these programs. Even greater payoff might be obtained if CMMI supported a learning network across grantees and researchers to encourage local or regional research efforts and to assure that relevant learning is shared across sites.

CMMI is to be lauded for taking this major step in stimulating innovation and evaluation. Their efforts, especially if expanded by complementary and synergistic research, have the potential to transition previously scattered and understudied programs to address SDH into sustainable key components of the health care delivery system.

Contributors: Members of the Social Interventions Research and Evaluation Network (SIREN) in Health Care Working Group, including Sara Ackerman, PhD, University of California, San Francisco; Andrew Beck, MD, MPH, University of Cincinnati and Cincinnati Children's Hospital Medical Center; Jim Bellows, PhD, MPH, Kaiser Permanente; Erika Cottrell, PhD, MPP, Oregon Health and Science University and Oregon Community Health Information Network (OCHIN); Karen Emmons, PhD, Harvard T.H. Chan School of Public Health; Rachel Gold, PhD, MPH, Kaiser Permanente and Oregon Community Health Information Network; Clarissa Hsu, PhD, Group Health Research Institute, University of Washington, and Bastyr University; Rob Kahn, MD, MPH, University of Cincinnati and Cincinnati Children's Hospital Medical Center; Andrew Pinto, MD, CCFP, FRCPC, MSc, University of Toronto and St. Michael's Hospital; Maria Raven, MD, MPH, MSc, University of California, San Francisco; Megan Sandel, MD, MPH, Boston University and National Center for Medical-Legal Partnership; Adam Schickedanz, MD, University of California, Los Angeles; Loel Solomon,
PhD, Kaiser Permanente; Sara Standish, MBA, Health Leads; and John Steiner, MD, MPH, Kaiser Permanente.

Corresponding Author: Laura Gottlieb, MD, MPH; Department of Family and Community MedicineUniversity of California, San Francisco, 3333 California Street, Suite 465, San Francisco, CA 94118, USA (e-mail: Laura.Gottlieb@ucsf.edu).

\section{Compliance with Ethical Standards:}

Funders: The authors also wish to thank Kaiser Permanente and the Robert Wood Johnson Foundation for supporting this work.

Conflict of Interest: The authors declare no conflict of interest.

\section{REFERENCES}

1. Link BG, Phelan J. Social conditions as fundamental causes of disease. J Health Soc Behav. 1995;Spec No:80-94.

2. McGinnis JM, Foege WH. Actual causes of death in the United States. JAMA. 1993:270(18):2207-2212.

3. Adler NE, Stewart J. Health disparities across the lifespan: meaning, methods, and mechanisms. Ann N Y Acad Sci. 2010;1186:5-23.

4. McGinnis JM, Williams-Russo $\mathbf{P}$, Knickman JR. The case for more active policy attention to health promotion. Health Aff. 2002;21(2):78-93.

5. Mackenbach JP, Stronks K, Kunst AE. The contribution of medical care to inequalities in health: differences between socio-economic groups in decline of mortality from conditions amenable to medical intervention. Soc Sci Med. 1989;29(3):369-376.

6. Galea S, Tracy M, Hoggatt KJ, Dimaggio C, Karpati A. Estimated deaths attributable to social factors in the United States. Am J Public Health. 2011;101(8):1456-1465.

7. Bradley EH, Taylor LA. The American health care paradox: why spending more is getting us less. New York: Public Affairs; 2013.

8. Institute of Medicine of the National Academies Committee on the Recommended Social and Behavioral Domains and Measures for Electronic Health Records. Capturing social and behavioral domains in Electronic Health Records: Phase 2. Washington, DC: The National Academies Press; 2014.

9. Canadian Medical Association. Physicians and Health Equity: Opportunities in Practice. https://www.cma.ca/Assets/assets-library/document/en/advocacy/Health-Equity-Opportunities-in-Practice-Final-e. pdf. Accessed October 20, 2016.

10. American Academy of Pediatrics Council On Community. Poverty and child health in the United States. Pediatrics. 2016;137(4).

11. Bachrach $\mathbf{D}$, Lipson $\mathbf{M}, \mathbf{P f i s t e r} \mathbf{H}$, Wallis $\mathbf{K}$. Addressing social determinants of health: The business case for provider investment. Manatt Health Solutions for the Commonwealth Fund, The Skoll Foundation, and the Pershing Square Foundation. 2013.

12. Institute for Alternative Futures. Community health centers: leveraging the social determinants of health. Alexandria: Institute for Alternative Futures; 2012.

13. Hussein T, Collins $\mathbf{M}$. The community cure for health care. Stanford Social Innovation Review; 2016. Available at: http://ssir.org/articles/ entry/the_community_cure_for_health_care. Accessed October 20, 2016.

14. Alley DE, Asomugha CN, Conway PH, Sanghavi DM. Accountable health communities-addressing social needs through Medicare and Medicaid. N Engl J Med. 2016;374(1):8-11.

15. Centers for Medicare and Medicaid Services. Affordable Care Act Funding Opportunity: Accountable Health Communities. 2016; Funding Opportunity Number: CMS-1P1-17-001. https://www.grantsolutions.gov/gs/ preaward/previewPublicAnnouncement.do?id=55237. Accessed October $20,2016$.

16. Braveman P, Gottlieb $\mathbf{L}$. The social determinants of health: it's time to consider the causes of the causes. Public Health Rep. 2014;129(Suppl 2):19-31.

17. Aharony L, Strasser S. Patient satisfaction: what we know about and what we still need to explore. Med Care Rev. 1993;50(1):49-79.

18. Fenton JJ, Jerant AF, Bertakis KD, Franks P. The cost of satisfaction: a national study of patient satisfaction, health care utilization, expenditures, and mortality. Arch Intern Med. 2012;172(5):405-411.

19. Seeman TE, Crimmins E, Huang MH, et al. Cumulative biological risk and socio-economic differences in mortality: MacArthur studies of successful aging. Soc Sci Med. 2004;58(10):1985-1997. 
20. Broyles ST, Staiano AE, Drazba KT, Gupta AK, Sothern M, Katzmarzyk PT. Elevated C-reactive protein in children from risky neighborhoods: evidence for a stress pathway linking neighborhoods and inflammation in children. PLoS One. 2012;7(9):e45419.

21. Cherkas LF, Aviv A, Valdes AM, et al. The effects of social status on biological aging as measured by white-blood-cell telomere length. Aging Cell. 2006;5(5):361-365.

22. Olayiwola JN, Grace RW, Dube $\mathbf{K}$, et al. Understanding the relationship between social determinants of health and physician burnout. Paper presented at: North American Primary Care Research Group Annual Meeting, 2015; Cancun, Mexico.

23. Buchbinder SB, Wilson M, Melick CF, Powe NR. Estimates of costs of primary care physician turnover. Am J Manag Care. 1999;5(11):14311438
24. Williams ES, Manwell LB, Konrad TR, Linzer M. The relationship of organizational culture, stress, satisfaction, and burnout with physicianreported error and suboptimal patient care: results from the MEMO study. Health Care Manag Rev. 2007;32(3):203-212.

25. Peters DH, Adam T, Alonge O, Agyepong IA, Tran N. Implementation research: what it is and how to do it. BMJ. 2013;347:f6753.

26. Gottlieb L, Quinones-Rivera A, Manchanda R, Wing H, Ackerman S. States' influences on Medicaid investments to address patients' social needs. Am J Prev Med. 2016; Published online Sept. 19, 2016.

27. Garg A, Boynton-Jarrett R, Dworkin PH. Avoiding the unintended consequences of screening for social determinants of health. JAMA. 2016;316(8):813-814. 